\title{
The Deadly COVID-19 Being in Pandemic Near Two Years may be Man-Made in Inhumanity
}

\author{
Xu Han-You* \\ Clinical Institute, Department of General Internal Medicine, International Liasom Hospital in Anji, China
}

*Corresponding author: Xu Han-You, Department of General Internal Medicine, International Liasom Hospital in Anji,

Huzhou city, Zhejiang Province, China

\section{ARTICLE INFO}

Received: 慧 November 08, 2021

Published: 慧 November 23, 2021

Citation: Xu Han-You. The Deadly COVID-19 Being in Pandemic Near Two Years may be Man-Made in Inhumanity. Biomed J Sci \& Tech Res 40(2)-2021. BJSTR. MS.ID.006410.

Keywords: COVID-19; Pandemic; Etiology; Public Health; Control; Inhumanity

\section{ABSTRACT}

Objective: In order to control and cure the disease killer of the COVID-19 pandemic world wide day and night in more than one year, the etiology of the COVID-19 pandemic must be found.

Methods: Summarizing and analyzing the special events and official reports of WHO on the development of COVID-19 pandemic and related positive connection events. I have found that the factual evidences can deduce the etiology of the COVID-19 pandemic at present.

Results: The 11 factual evidences have been summarized and analyzed. Here are several evidences [1]. That the United States of America has been quitting WHO (World Health Organization) at the critical time of COVID-19 pandemic has shown the evidence that something has been being wrong in world wide management of COVID-19 pandemic. So that I can deduce that at least the etiology of the COVID-19 pandemic and its management may be false and wrong. Even it is true [2]. As the modern science and technology developed, the radio controlling the space crafts and physiology of human being and man-made patho-physiology changes have been being in an easy way like the hand movements of normal adult man. Therefore, from the points of evidences, the possibility must have that some inhumanity people and countries, with stupid and politic ugly aims, misusing the power of the modern developed science and technology, have been damaging the mankind by radio controlling the human physiology and manmade patho-physiology changes like the contagious disease pandemic on the Earth. Which results the present world wide pandemic of COVID-19 [3]. According to WHO report, the North Korea has not suffered from COVID-19. But the North Korea is just in the South-East Asia, and the same root with the Republic of Korea, has been being open up with outside world after the President of the North Korea historically met the President of The United States of America two years age. Further more, the North Korea has been being the socialism country having brother like relationship with People's Republic of China. The tie has been being more and more strange after Korean War beginning in 1950 when P. R. C. China in danger but helped North Korea militarily recovered from death. But now, it is unimaginable that the opening up North Korea even has not been had any case of COVID-19 up to now. While around the North Korea and P. R. C. China, every country has been being suffered from COVID-19 pandemic. And the other 8 evidences have been resulted.

Conclusion: At the critical time of continuing genicide dying and suffering from the COVID-19 pandemic day and night in more than one year, I suggest that these continuing genicide dying and suffering from the COVID-19 pandemic may be caused by some ugly and inhumanity politicians or military using micro and radio-controlled damn weapons, stimulating and developing the disease of the COVID-19 pandemic and deaths in a short time. This conclusion is valuable to be referenced by the UN, WHO, No Government Organizations, all countries and all Earth people and others. If identified as truth, the huge genicide inhumanity deaths and suffering from the genicide can be cured in a few days. The world can be recovered in a few days. 


\section{Introduction}

The deadly COVID-19 has been being in pandemic in Wuhan in December, 2019 and then around the world. Globally, as of 5:08pm CEST, 12 July 2021, there have been 186,638,285 confirmed cases of COVID-19, including 4,035,037 deaths, reported to WHO. As of 11 July 2021, a total of 3,114,766,865 vaccine doses have been administered [1]. And the control of the outbreak and pandemic has been in bad results up to now. But China is just well controlled. Though the Diabetes, Cancers, Cardiovascular diseases, Hepatitis, Chronic obstructive pulmonary disease, and hypertension, et al. have been being at large with heavy burden and have been being suffered from by all Chinese. Which has been being called the facts that China has been being Sick man of East Asia again in recent years [2]. Which these facts have been the some sydromes of failure by the Communist Party of China. More than 1.5 year ago, the deadly COVID-19 has been being in pandemic first in Wuhan in December, 2019 and then in pandemic around the world rapidly. Up to now, all the countries have not controlled the deadly COVID-19. But just China has been being controlled the deadly COVID-19 after first suffered from the pandemic. Which has been showing how best the Communist Party of China is. And which has been reducing the bad effects of that China has been being Sick man of East Asia again in recent years in chronic diseases.

As the deadly COVID-19 has not been controlled up to now. Even a total of 3,114,766,865 vaccine doses of COVID-19 have been administered within so much too long time, near 2 years. The situation has been being worse and worse. Because everyday, there are thousands and thousands new cases of COVID-19 confirmed, and thousands are dying without time limited. As a doctor striving to cure and treat the patients and prevent the diseases from harm the masses, I cannot help but doing something to guard the public from devestated diseases. In order to control and cure the deadly COVID-19 as soon as possible. I think the real etiology of the deadly COVID-19 must be cleared. It is natural and imperative that any possibilities which can find the etiology of the deadly COVID-19 and lead to control the dying world by COVID-19 must not be given up. Therefore, in this paper, from the points of facts, I can say that the deadly COVID-19 being in pandemic around the world near two years may be man-made in inhumanity anti-mankind. The follows are the facts.

\section{The Deadly COVID-19 has Been Swiftly Changing or Mutating the Genes and their DNAs is Much too Unnatural or Run Against the Science of Biology}

As the WHO and researchers have constantly reported the Genetic Variants of SARS-CoV-2 or COVID-19 [3-8].But, in the natural regulations of evolution and mutation of biology. The evolution and mutation of the natural virus and other microbiology is in a low speed. Like the clinical difficulty about the drug resistance by and virus resistance, it has been taking a long time to mutate a drug resistance gene and produce the enzyme to destroy the antibiotic. While there are reported constantly changing the genetic of COVID-19 around the world in a short time. So the constant Genetic Variants of COVID-19 mutations are not looking like biology science.

\section{The SARS-CoV-2 has not been Totally Proved that they Caused the COVID-19}

Up to now, Globally, as of 5:08pm CEST, 12 July 2021, there have been 186,638,285 confirmed cases of COVID-19. But the pathology of the COVID-19 has not been proved and text-booked. And the animal model of COVID-19 has not reached significant scientific results. As Simon J Cleary, et al. researched that only partly animal model with the mechanisms involved in human severe COVID-19 [9]. Therefore, if the SARS-CoV-2 has caused COVID-19 has not been totally proved. Furthermore, I can prove my findings that by the fact searched WHO net by the key words of "Animal model, COVID-19" or "Animal model of COVID-19" at July 14, 2021. The searched results are "No results for Animal model, COVID-19" or "No results for Animal model of COVID-19". Also, the results of "pathology of COVID-19" or "pathology, COVID-19". The WHO has been just leading the world to set the standard of the pathology of COVID-19, prevention and treatment or cure. But there have been no results about up to now. As Taewoo Kim et al [10]. have reported that the functional characteristics of the novel virus of COVID-19, such as its mechanisms of cell entry and transmission, kinetics in replication and transcription, host responses, and therapeutic targets have not understood, to say nothing of therapeutics clinical application.

\section{The SARS-CoV-2 can be Said that they are not a Single Virus but a Man-Made a Group of Viruses has not been Totally Proved that they Caused the COVID-19}

According to data of WHO, "Tracking SARS-CoV-2 variants", up to now, there are ten SARS-CoV-2 variants of Currently designated Variants of Concern have been found.[10]And there are four SARS-CoV-2 variants of Currently designated Variants of Interest have been found [11].These lots of SARS-CoV-2 variants are just "Interest" or "Concern". So, the SARS-CoV-2 can be said that they are not the same virus with the same single disease caused gene but man-made groups of virus have not been totally proved that they caused the same COVID-19. So, as the genes and DNAs of the present pandemic are not united around the world. We should not name all the pandemic as only one COVID-19.

\section{The COVID-19 has Not had the Characters of the Contagious Disease}

In the science of contagious disease, one contagious disease must have 3 factors that affect infectivity: The single pathogen of contagious disease, the susceptible persons, and the infectious 
pathways. But in fact, the present so called pandemic SARS-CoV-2 of COVID-19 has lots of pathogens. So, the pathogen of COVID-19 has not proved as single one disease caused virus. And it must not be proved as the same one contagious disease.

That the 3,114,766,865 vaccine doses of COVID-19 have been administrated into the human-bodies around the world is no effective shows the diagnosis, prevention and treatment of the SARS-CoV-2 of COVID-19 have been being in a wrong way. The main reason for this situation is that the SARS-CoV-2 of COVID-19 is not united as a same virus with same single disease caused gene. In other word, I can say that there is no real SARS-CoV-2 of COVID-19. For at present developed medical and biological science, if the world has really found a real disease caused virus. Even it has genetic variants. The effective vaccine with significant clinical result can be created in a relatively short time. But, present vaccine for COVID-19 has been in little clinical result. Even the pandemic has been being in more and more severe. Furthermore, the production of the vaccine for COVID-19 is so fast applied into patients that the production process is not scientific enough. As there are little clinical trials, even no phase IV clinical trials. So, the researchers and the factories of the 3,114,766,865 vaccine doses for COVID-19 can be said fake medicine.

\section{The COVID-19 Pandemic Around the World in a Short Time Seems to be Incredibility}

In the history of the pandemic contagious disease, it is the first time the single pandemic spread around the world in such a short time.

The 3,114,766,865 Vaccine Doses have been administrated into the human-bodies in such a short time without clinical controlling effectively but more and more severe is incredibility. Near half of globe masses have been administrated total 3,114,766,865 vaccine doses to control COVID-19 pandemic. But with little effective. Which all are the first in history. All which has proved that the SARS-CoV-2 of COVID-19 pandemic and its control of management are wrong.

\section{Only North Korea with World Standard Level Communications has not been COVID-19 is also Incredibility}

According to WHO report [12],the North Korea and other 12 islands countries surround by vast water(Cook Islands, Kiribati, Micronesia, Nauru, Niue, Palau, Pitcaim Islands, Saint Helena, Tokelau, Tonga, Tuvalu) have not suffered from COVID-19. That is, they have not had any confirmed case of COVID-19 up to now. Why has this situation developed? The reason why these countries have not any case of COVID-19 must be valuable to save the dying and suffering of rest countries of COVID-19. We all have known that all the islands' countries are small and isolated or sea islands far from people of other countries or the pandemic countries. Which they have been being well cut off outsides of world. Furthermore, these islands world also have been living in isolated politic intimations and without any threaten to other countries. These are the clear characters of the islands countries.

But the North Korea is just in the other way. Being in the SouthEast Asia, and the same root with the Republic of Korea has been being open with outside world after the President of the North Korea historically met the President of The United States of America three years age.

Furthermore, the North Korea has been being the socialism country having brother like relationship with People's Republic of China. The tie has been being more and more strange after Korean War beginning in 1950 when P. R. C. China in danger but helped North Korea militarily. So that the North Korea recovered from subjugation. But now, it is unimaginable that the opening up North Korea even has been had any case of COVID-19 up to now. While around the North Korea and P. R. C. China, every country has been being suffered from COVID-19 pandemic. The delicate and subtle relationship of PRC China and North Korea seem to indicate that PRC China has been helping North Korea hungrily living without the COVID-19. While the simple science fact is that the hungry breeds diseases and pandemic of contagious diseases. But it is also unimaginable contradiction that as the PRC China usually honored as peace loved and honest country, why PRC China do not help to cure world from severe pandemic of COVID-19. As up to about one year and at present, there have been being little Chinese experts of COVID-19 support foreign countries. Even the pandemic of COVID-19 has been being severe and severe outside of China and North Korea. Not welcomed by other countries.

As the Modern Science and Technology Developed, the Radio controlling the Space Craft and Physiology of Human Being and Man-Made Patho-Physiology Changes have been being in an Easy Way Like the hand Movements of Normal Adult Man

As I am doctor with more than 30 years' experience. Some radio controlling technologies have been applied for civil use to diagnose and treat patients. Also, as the Earth has been being full of micro-biology and viruses. The identification of a virus and other micro-biology must have a chance doing the wrong identification. At present, the traceability of the COVID-19 has not been doing any significant result. But has been finding lots of less valuable variants. Therefore, from the points of evidence, the possibility must have that some inhumanity people and countries, with stupid and politic ugly aims, misusing the power of the modern developed science and technology, have been damaging the mankind by radio controlling the human physiology and man-made patho-physiology changes 
on the Earth. Which result the present worldwide pandemic of COVID-19. As the simple fact tell us that the radio controlling the human physiology and man-made patho-physiology changes for the pandemic of COVID-19 can reach their inhumanity result in a short time around the world and where, when, or how severe the politic ugly people of inhumanity want.

\section{Science and Politics are not Easily Totally Divided}

Facing the evidences about worldwide pandemic of COVID-19 and the less science of COVID-19 pandemic, the politic motive of the pandemic of COVID-19 has been being speak out by politicians, medias, masses and even the scientists, et al. Therefore, though people have been pursuing dividing of the Science and politics. But in fact, history has told us, the science and politics are not easily totally divided. Some politicians, to reach their ulterior motives, have been using pseudoscience to defraud the masses.

\section{That the United States of America has been Quitting}

WHO (World Health Organization) at the critical time of COVID-19 pandemic has shown the evidence that something has been being wrong in world-wide management of COVID-19 pandemic. Because based on the developed social civilization and medical science, the America must have the basic fair, equality and human-right humanity doing facing the management of COVID-19 pandemic world-wide. I consider that when finding the COVID-19 pandemic and its management wrong. So that the America has quitted the WHO. As the WHO at least must have the fair, equality and human-right humanity doing facing the management of COVID-19 pandemic world-wide. What is the wrongness of the COVID-19 pandemic and its management? At least the etiology of the COVID-19 pandemic and its management may be false and wrong. Even it is really false and wrong.

\section{Discussion and Conclusion}

As the COVID-19 pandemic world-wide has been killing people more than 4million and billions of people have been being suffered from the COVID-19 pandemic world-wide. Every humanity man must have the motive and hope to control and cure the killer of COVID-19 as soon as possible. But up to now, there is little result to control and cure the killer of COVID-19. This is the historic first killer of COVID-19 suffered by the people all over the world in a short time. Therefore, man-made COVID-19 pandemic has been suggested. Some politicians, media and scientists have had the suggestion of the killer virus have been leaked out from virus lab and killed the innocent masses. The suggestion has not been accepted as true. We must consider that the suggestion with humanity motive and controlling and curing the killer of COVID-19 pandemic is good-willing. At the critical time of dying and suffering from the COVID-19 pandemic day and night in more than one year,
Every and any possibility that can control and cure the killer of COVID-19 pandemic must be accepted and identified in the goodwilling motive. Because the real possibility can be found just in a while. In conclusion, at the critical time of continuing genocide dying and suffering from the COVID-19 pandemic day and night in more than one year, I suggest that this continuing genocide dying and suffering from the COVID-19 pandemic may be caused by some ugly and inhumanity politicians or military using micro and radiocontrolled damn weapons, stimulating, and developing the disease of the COVID-19 pandemic and deaths in a short time.

This conclusion has been reached by the 11 factual evidence coming from my summarizing and analyzing the special events and official reports of WHO on the development of COVID-19 pandemic and related positive connection events. This conclusion is valuable to be referenced by the UN, WHO, No Government Organizations, all countries and all Earth people and others. If identified as truth, the huge genocide inhumanity deaths and suffering from the genocide can be cured in a few days. The world can be recovered in a few days. This research has a limit. This is. As I am only an ordinary or even a half citizen. I am sure I have not the ability to prove it. But I submit my research to the media to publish my research article. Let the people for a justice cause or the people have ability for a justice cause to prove it and justice it. Even the proving of my research is not true. The cost is a few.

\section{Statements and Acknowledgement}

a. Contributor Ship: The single author, Xu Han-You, contributed all to the research.

b. Competing Interests: There is no competing interests.

c. Funding Statement: The research supported by author himself.

\section{References}

1. (2021) WHO Coronavirus Disease (COVID-19) Dashboard.

2. Xu Han You (2021) China has been being Sick man of East Asia again in Recent Years. Journal of Pharmacy and Drug Development 3(1): 1-4.

3. Bridget M Kuehn (2020) MSJ Genetic Analysis Tracks SARS-CoV-2 Mutations in Human Hosts. JAMA 323(23): 2363.

4. Adam S Lauring, Emma B Hodcroft (2021) Genetic Variants of SARSCoV-2 What Do They Mean? JAMA 325(6): 529-531.

5. John P Moore, Paul A (2021) SARS-CoV-2 Vaccines and the Growing Threat of Viral Variants. JAMA 325(9): 821-822.

6. John Moore (2021) Experts Discuss COVID-19 Variants and Vaccine Efficacy Immunosuppressed Patients, and More. JAMA 325(17) 17111712.

7. Caspar I Van DerMade, Annet Simons, Janneke Schuurs Hoeijmakers, Guus van den Heuvel, Tuomo Mantere, et al (2020) Presence of Genetic Variants Among Young Men With Severe COVID-19. JAMA 324(7): 663673. 
8. Carlos del Rio, Preethi Malani (2021) COVID-19 in 2021 Continuing Uncertainty. JAMA 325(14): 1389-1390.

9. Simon J Cleary, Simon C Pitchford, Richard T Amison, Robert Carrington, C Lorena Robaina Cabrera, et al. (2020) Animal models of mechanisms of SARS-CoV-2 infection and COVID-19 pathology. Br J Pharmacol 177(21): 4851-4865.

ISSN: 2574-1241

DOI: $10.26717 /$ BJSTR.2021.40.006410

Xu Han-You. Biomed J Sci \& Tech Res

(c) (P) This work is licensed under Creative

Submission Link: https://biomedres.us/submit-manuscript.php
10. Taewoo Kim, Jeong Seok Lee, Young Seok Ju (2021) Experimental Models for SARS-CoV-2 Infection. Mol Cells 44(6): 377-383.

11. Tracking SARS-CoV-2 variants, WHO.

12. WHO Coronavirus (COVID-19) Dashboard data table.

$\begin{array}{ll}\text { BIOMEDICAL } & \text { Assets of Publishing with us } \\ \text { RESEARCHES } & \text { - Global archiving of articles } \\ \text { - Immediate, unrestricted online access } & \text { - Rigorous Peer Review Process } \\ & \text { - Authors Retain Copyrights } \\ \end{array}$

